\title{
The Urgency of Advancing Equality
}

Over the past several years, grave threats to equal rights, both new and longstanding, have come into sharp relief. Against the backdrop of persisting gaps in women's representation in government and equal participation in the economy, a global movement has exposed the prevalence of sexual harassment in our workplaces, schools, streets, and even legislatures. Violence and natural disasters have created unprecedented numbers of refugees, who face not only significant barriers to accessing jobs and education upon resettling in new countries, but also discrimination due to their race/ethnicity, religion, and national origin. Meanwhile, in a range of countries, extremist movements and politicians have capitalized on the public's fears, insecurities, and misperceptions to call for the expulsion of immigrants and ethnic, racial, and religious minorities, using dehumanizing rhetoric hearkening back to the rise of the Nazis.

At the same time, the beginning of the twenty-first century has witnessed the culmination of decades of dramatic progress in addressing many of the greatest barriers to equality-from discriminatory laws to the inaccessibility of basic services and institutions. Just in the two years prior to this writing, 65 countries reformed laws that limited women's ability to participate and succeed in the economy, building on hundreds of reforms adopted since the 1960s. ${ }^{1}$ Globally, the number of people living in extreme poverty fell by half between 1990 and 2015, while that of people accessing basic education rose by over 40 million. ${ }^{2}$ 
Groundbreaking national laws, as well as an international treaty, have accelerated progress toward the full inclusion of people with disabilities in education and employment.

This is a book about how far we've come on equal rights-and how far we have to go. This is also a book about what we all can do to advance equality in the urgency of this moment, both as individuals and as countries. And this is a book about how nations set the ground rules and whether those ground rules are designed to ensure that you, your children, and your grandchildren-whoever they become, wherever they live, and whomever they love-will have a fair chance.

\section{CHANGES IN LEGAL RIGHTS IN OUR LIFETIME}

Over the past 60 years, countries around the world have witnessed revolutions in equal rights. In the United States and South Africa, the overdue demise of Jim Crow and apartheid, two legal regimes premised on racial hierarchy, inaugurated a new era for equality and civil rights. In the Middle East and North Africa, women's rights movements have made steady gains over the past decade for gender equality in the law, including with respect to violence, freedom of movement, and the right to participate in politics; ${ }^{3}$ similar regional and national movements dating back to the nineteenth century have brought a wave of social, economic, and political "firsts" for women around the world. Across low- and middle-income countries, the right to education has flourished, as governments have increasingly eliminated tuition fees that once put public school out of reach for girls and students from poor families. And across every region, countries have begun recognizing equal human rights regardless of sexual orientation and gender identity.

This progress is remarkable and worth celebrating. Yet we know that exclusion persists, and that countless daily experiences of discrimination and bias contribute to devastating disparities in education, health, and work.

\section{THE DIGNITY OF EVERY HUMAN BEING}

In recent years, the troubling and vocal resurgence of overt discrimination has called into question whether equality truly is a shared value. As hate rallies and ethnic, racial, and religious slurs have dominated the headlines, it is reasonable to wonder whether there was ever genuine consensus about our universal dignity and humanity.

Numerous historical examples show how perceived physical or economic vulnerability - whether based in evidence or stoked by opportunistic leaders and politicians - can inspire distrust, division, and, in the worst cases, gross human rights abuses. In some countries, these conditions have resulted in atrocities committed by governments; other countries have endured sharp escalations in interpersonal hostilities and violence. 
While we must recognize these dynamics and dangers, we must also firmly reject the idea that hateful views are representative in any of our countries. The data convincingly tell us otherwise. The World Values Survey asks people about their core beliefs in the privacy of their homes in over 100 countries, representing $90 \%$ of the global population. These surveys reveal that the view that every human being deserves dignity is both widespread and not unique to any country. For example, when asked which qualities it was especially important for children to learn at home, $86 \%$ of respondents in Australia, $86 \%$ in Colombia, $89 \%$ in India, and $80 \%$ in Libya indicated "tolerance and respect for other people." 4

One critical development over the past 75 years has been the formalization of these values in international treaties and agreements. In 1948, the newly formed United Nations adopted the Universal Declaration of Human Rights (UDHR), which unequivocally affirmed that "[a]ll human beings are born free and equal in dignity and rights," and prohibited discrimination on the basis of "race, colour, sex, language, religion, political or other opinion, national or social origin, property, birth or other status." The UDHR also guaranteed the rights to education, health, and a wide range of other social, economic, civil, and political rights. In 1966, the U.N. built on these commitments with two additional treaties, the International Covenant on Civil and Political Rights ${ }^{5}$ and the International Covenant on Economic, Social and Cultural Rights. ${ }^{6}$ Together, these three instruments are known as the "International Bill of Rights."

Additionally, throughout the decades, the U.N. has adopted treaties specifically and comprehensively addressing the equal rights of historically marginalized or vulnerable groups, including refugees, ${ }^{7}$ racial/ethnic minorities, ${ }^{8}$ women, ${ }^{9}$ children, ${ }^{10}$ migrant workers and their families, ${ }^{11}$ and people with disabilities. ${ }^{12}$

These international commitments have had important normative impacts, and many have been widely or nearly universally ratified. Even more recently, in 2015, all 193 U.N. countries adopted the Sustainable Development Goals, pledging to end poverty, reduce inequality, ensure access to healthcare and education, and achieve a range of other human rights objectives by 2030.13 The question, then, is not whether human dignity and equality are overarching, widely shared valuesbut whether these values and commitments have been translated into enforceable national rights.

\section{WHY CONSTITUTIONS}

In many ways, constitutions provide ideal vehicles for doing so. As we explore throughout this book, constitutions' pathways to impact vary across countries with different legal traditions, levels of civil society engagement, and avenues to justice. At the same time, constitutions provide the foundation of almost every nation's legal system, and many of their core functions are largely consistent across countries. 


\section{A Statement of Values}

To start, constitutions both express values and embody contracts between governments and their people to realize those values. Through the principles it protects, a constitution can importantly shape national discourse, in turn influencing social norms. New constitutions can also serve to inaugurate a new era for equal rights that sharply diverges from the past. For example, upon signing South Africa's postapartheid constitution in 1996, President Nelson Mandela remarked: "In centuries of struggle against racial domination, South Africans of all colours and backgrounds proclaimed freedom and justice as their unquenchable aspiration. They pledged loyalty to a country which belongs to all who live in it. . . Out of such experience was born the understanding that there could be no lasting peace, no lasting security, no prosperity in this land unless all enjoyed freedom and justice as equals." 14

Through a new constitution grounded in principles including equality, diversity, freedom, and reconciliation, South Africa created a new statement of values to guide its transition into democracy.

\section{Dismantling Discriminatory Laws}

Second, in the vast majority of countries, constitutions trump other sources of law-making them critical tools for overturning discriminatory legislation, including both newly enacted and decades-old laws. In India, the Supreme Court ruled in 2017 that the traditional practice of "instant divorce" in Islamic marriages, which allowed men to legally divorce their wives simply by saying the Arabic word for divorce three times, violated the constitution's protection of gender equality, in a landmark ruling strengthening women's economic security and access to justice. ${ }^{15}$ In Tunisia and Morocco, women's rights groups are leading advocacy campaigns to overturn discriminatory inheritance laws, based on their new constitutions' guarantees of women's equal rights. ${ }^{16}$

\section{Domesticating Global Treaty Commitments}

Third, constitutions often directly determine the status of international treatiesincluding whether ratified treaties have the force of law, take precedence over conflicting legislation, or can be directly invoked in court. As explored in the following chapters, in countries ranging from Mexico to the Czech Republic, these constitutional provisions have helped ensure that national courts interpret domestic laws to protect and advance human rights.

\section{Protecting against Backsliding}

Fourth, constitutions can offer protection against policy and legal changes that would undermine equal rights. However, when constitutions lack clear protections for groups that are vulnerable to discrimination, these groups' rights may face threats during political shifts or budgetary cutbacks. 
For example, for decades, the United States has had excellent laws ensuring that children with disabilities have equal access to quality education, and that adults with disabilities can contribute fully at work. However, the U.S. Constitution has no foundational guarantee of equal rights for people with disabilities-and strong as they are, these laws would be far easier to dismantle or outright repeal than a constitutional protection against discrimination. This vulnerability has intensified under the Donald Trump administration, which has targeted both laws. In the absence of a stronger constitutional foundation for equal rights on the basis of disability in work and education, these attacks threaten to unravel the gains of the past three decades.

The same potential for retrenchment exists in the courts. When rights are not clearly protected in the constitutional text, a court's interpretations of who deserves equal treatment may expand and contract over time, especially as the court's composition evolves. Similarly, even when courts rule in favor of equality, the legislature may enact discriminatory laws in response, unless the constitution prevents them from doing so.

For example, in Bermuda, the Supreme Court's landmark 2017 decision legalizing same-sex marriage came under threat when Parliament passed a law the following year banning same-sex marriage-making Bermuda the first country to grant and then revoke equal marriage rights. Like most countries, Bermuda has yet to specifically prohibit discrimination on the basis of sexual orientation in its constitution. However, the Court applied another constitutional right-freedom of religion-to overturn the discriminatory law, which the justices deemed an imposition of specific religious views. ${ }^{17}$ Yet as this book will explore, such favorable outcomes are far from guaranteed when constitutions are ambiguous about whose equal rights are recognized.

\section{Setting the Terms of the Debate}

Fifth, constitutions matter because of how they shape decision-making outside the courts-including by other branches of government. For example, between 2015 and 2017, the constitution was a topic of discussion and debate in $87 \%$ of parliamentary sessions in India. ${ }^{18}$ These conversations covered wide-ranging topics central to equality, including the equal rights of members of lower castes, religious minorities, and transgender people.

Similarly, over the same period, the constitution arose in $88 \%$ of parliamentary sessions in Canada, $97 \%$ of those in Brazil, and $99 \%$ of those in Kenya. ${ }^{19}$ In Canada, the constitution was cited in support of bills aiming to protect against gender discrimination, expunge unjust convictions targeting the LGBT+ community, and ensure equal pay for work of equal value for women in the Canadian Public Service. Likewise, in Brazil, the constitution came up in legislators' discussions about the rights to healthcare, nondiscrimination, and access to water, while in Kenya, legislators referenced the constitution when discussing education, healthcare, and gender equality in politics. 


\section{A Tool for Civic Engagement}

Finally, constitutions provide tools for civic engagement, education, and activism. In India, activists undertook a 115-day march to establish a constitutional right to education..$^{20}$ In Kenya, civil society groups are publishing copies of the constitution in Braille, and handing out pocket-size text versions nationwide. ${ }^{21}$ In Germany, newly arriving refugees receive copies of the bill of rights in Arabic. ${ }^{22}$

Yet even as constitutions articulate fundamental values and provide legal bases for decisions that affect millions of lives, few people know exactly which rights their constitution protects, or how their constitution's protections compare to others'. In an era of increased popular engagement in constitution drafting and amending, addressing these information gaps is crucial.

\section{DO OUR CONSTITUTIONS VALUE EVERY PERSON?}

In recent years, countries have increasingly convened widely representative constitutional congresses to draft their constitutions. In these processes, the chance that the constitution equally values every person has increased.

Many of us live in countries, however, whose constitutions were written centuries ago or have not been amended in decades. Early constitutions were often written by small, nonrepresentative groups. Many later constitutions used these documents as models. And because of their foundational role in defining how a government works, identifying whether our countries' constitutions establish a framework providing for equal and full opportunities for everyone is essential.

In this book, we report on over a decade of research. We have led and been part of a large, international, multilingual, multidisciplinary team that has reviewed constitutions in each one of the 193 U.N. countries. At least two team members have read every constitution and examined where each comes down in terms of guaranteeing equal rights to us all, regardless of gender, socioeconomic status, race/ethnicity, or religion, belief, or nonbelief. We have also looked at whether equal rights are guaranteed regardless of our sexual orientation or gender identity, whether we have a disability, and whether we are a refugee or a migrant. Finally, we have examined whether every person is guaranteed an equal opportunity for an education and access to the healthcare they need to survive and thrive.

Throughout this book, we present data on constitutions produced through this initiative at the WORLD Policy Analysis Center. ${ }^{23}$ In each chapter, you will learn what percentage of the world's countries has adopted fundamental constitutional protections. We have also included global maps in many core areas so you can easily see how your country's constitution compares to others. To illustrate the impact of these choices in practice, we searched over 16,000 court cases from around the world. Throughout the chapters, we present examples of case law from over 40 countries representing diverse regions and legal traditions. More details on the data and our approach to case law are available in the Appendix. Interactive policy 
maps, data tools, and further information on WORLD are available on our website: worldpolicycenter.org.

\section{THE CHAPTERS}

\section{Chapter 2: Historic Exclusion and Persisting Inequalities: Advancing} Equal Rights on the Basis of Race and Ethnicity

In numerous countries throughout history, racial/ethnic discrimination has played a foundational role in structuring economies and legal systems, leading to physical segregation, denials of economic rights, and, in the worst cases, enslavement. In the United States, even after a constitutional amendment prohibited slavery, Jim Crow laws systematically excluded African American citizens from political power and economic opportunities for decades. In South Africa, apartheid prohibited the black population from owning land and relegated black families to substandard housing in designated neighborhoods.

Jim Crow fell in 1965 and apartheid followed in 1991-but the impacts of these systems continue to reverberate. What's more, even as legal discrimination on the basis of race/ethnicity fades, discriminatory practices persist, with consequences for health, justice, and economic security. Globally, how many countries guarantee equal rights across race/ethnicity and prohibit all direct discrimination? Without being explicitly discriminatory, policies and practices can still disproportionately disadvantage certain racial/ethnic groups; how often do constitutions address "indirect discrimination" and have these protections had impact in court? How are constitutions addressing segregation, which persists in many countries despite guarantees of racial/ethnic equality and case law striking down "separate but equal"? And for countries with long histories of racial/ethnic oppression and exclusion, are constitutions and courts providing a foundation for efforts to dismantle the persisting impacts of past discriminatory laws and practices?

\section{Chapter 3: Why Addressing Gender Is Foundational}

Women and girls are the largest global population to have been systematically excluded from enjoying basic rights in constitutional texts and by other laws. One of every two people, women and girls have been denied the right to vote, excluded from workplaces and schools, and prevented from full participation in the economy.

For millennia, women have also been leaders in governments, commerce, and civil society. But in most societies, they were the exceptions. Most women were not allowed to fully participate. Chapter 3 examines whether the world's constitutions have dismantled gender inequality in the law. Do all constitutions guarantee women and girls equal rights? If so, do these protections support equal opportunities and pathways to advancement by covering discrimination by both public and private employers and schools? Women also disproportionately face 
discrimination based on their expected roles within families. Do any constitutions successfully address discrimination on the basis of pregnancy, child-bearing, marital, or family status? How are civil society groups, lawyers, and courts using prohibitions on sex discrimination to address these intersectional issues? And finally, how can constitutions best address not only sex discrimination, but also gender discrimination against anyone who does not conform to cultural expectations about what it means to be a man or a woman?

\section{Chapter 4: One in Thirty: Protecting Fundamental Rights for the World's Migrants and Refugees}

Ensuring all human beings have equal rights is impossible without protecting the rights of migrants and refugees. In a room of 30 people, one, on average, will be a migrant. ${ }^{24}$ If you live in Montreal, Paris, or Frankfurt, around one in four of your neighbors was born in another country, while more than four of five people in Dubai migrated from elsewhere. ${ }^{25}$ Worldwide, there were nearly 258 million migrants in 2017-an increase of over 100 million since $1990 .{ }^{26}$

In short, one of the most striking transformations of the past half century has been the freedom of movement. This is in part due to the globalization of the economy. But even without trade agreements, the feasibility and accessibility of all forms of transportation have improved. Buses now provide dramatically expanded service to many rural areas, while air travel has become increasingly affordable. The types of transportation accessible to different individuals varies. Still, with this greater overall mobility, borders inevitably mean something different. A century ago, when it invariably took months to travel between countries and enormous resources to cross an ocean, mobility was limited. Now, and into the future, if you or your children are hungry or fleeing war, being drawn to another country is inevitable.

Global treaties recognize much of this. Around the world, 145 countries have agreed to a refugee convention that guarantees the right to education and wageearning employment. But have countries' constitutions caught up? And what do countries do about economic migrants, for whom there is less international agreement? Chapter 4 will examine the approaches countries' courts and constitutions have taken to supporting newcomers to both meet their basic needs and contribute to their full potential. How many constitutions protect the rights to education, health, work, and non-discrimination for migrants and refugees? Does it make a difference in practice when a constitution refers to "people" rather than "citizens"? And what protections can constitutions provide to the 10 million people around the world who are not officially citizens of any country?

\section{Chapter 5: Negotiating the Balance of Religious Freedom and Equal Rights}

The history of religious discrimination is long and pervasive. People were denied the ability to work in trades based on their religion. People were segregated into 
ghettos based on religion. ${ }^{27}$ And some countries had important pieces of their origins in fleeing religious persecution or founding safe havens for religious practice. It was this history that inspired the separation of religion and state in the U.S. Constitution, in contrast to England's official state religion. Yet history has also left discriminatory imprints. In Latin America, indigenous religions faced widespread persecution during Spanish colonialism, which established Catholicism as the governing faith and led to the continuing influence of the Catholic Churchincluding in constitutions-long after independence. ${ }^{28}$

Indeed, many of the worst forms of discrimination were state-sponsored or state-supported. State laws set up the ghettos. State rules prohibited people of certain religions from working in specific professions. Government rulers led many of the religious crusades and much of the persecution.

In chapter 5, we strive to answer a fundamental question: how can governments ensure that all religions can thrive while protecting all people's fundamental rights? Due to a history of killings and restrictions on movement, residence, and work, there is clearly a profound need to ensure safety, full equal opportunities, and equal rights before the law regardless of religion. At the same time, given the history of discriminatory abuses and denial of basic human rights by governments in the name of religion, achieving freedom of religion and belief, and equal rights and dignity for all, requires that the role of the state in prioritizing one religion be curtailed.

To understand the full range of current approaches, we examine the details of how all the world's constitutions negotiate this balance. We identify how many of the world's constitutions protect against religious discrimination and ensure that all people regardless of religious belief or nonbelief enjoy equal rights. We also address the relationship between religion and the state, examining how a role for religious bodies in governments may contribute to inequalities. Particularly important, we examine whether religious law, when it does coexist with secular law, is governed by constitutional rights, and whether equal rights take precedence when the two conflict. Finally, we examine the wide variation among constitutions that describe their government as "secular," illustrating how countries often subtly privilege one belief system over others.

\section{Chapter 6: Moving Forward in the Face of Backlash: Equal Rights Regardless of Sexual Orientation and Gender Identity}

Both within individual countries and globally, equal rights have often moved forward erratically - not for everyone together. In eighteenth-century France, revolutionaries fought for the Declaration of the Rights of the Man and of the Citizena widely celebrated document that nevertheless completely ignored the rights of women and citizens of the French colonies, who were deemed "passive citizens." In Peru, the 1823 constitution not only limited the right to vote to men but also imposed a literacy requirement, at a time when formal education was far from 
universal. ${ }^{29}$ In what is now the United States, soon-to-be Americans fought for a democracy that extended full citizenship only to white, male property owners. Native Americans, African Americans, and those without property were explicitly excluded. Women were not even considered.

On a global scale, countries adopted equal rights conventions one at a time for refugees (1951), racial/ethnic minorities (1965), women (1979), migrant workers (1990), and people with disabilities (2006). The one group treated in this book for whom there is still neither a specific international convention nor explicit protections in any international human rights treaty is sexual and gender minorities, including those who identify as lesbian, gay, bisexual, or transgender. The lack of a global agreement makes achieving equality for the LGBT+ community no less urgent and no less fundamental. If anything, the lack of agreement and the fact that there are currently 68 countries that criminalize the humanity and love of their LGBT+ residents make it all the more urgent. ${ }^{30}$

Chapter 6 examines how far equal rights on the basis of sexual orientation and gender identity have come in constitutions. Are they ahead of global agreements? While some countries strongly deny basic human rights, do others clearly protect equality? And what works to advance further reforms? In the absence of explicit constitutional protections, what strategies have advocates successfully used to move equal rights forward for the LGBT+ population using their constitution? Do social norms need to change first, or can legal change spur greater public support for equal rights?

\section{Chapter 7: From Nondiscrimination to Full Inclusion: Guaranteeing the Equal Rights of People with Disabilities}

One of the few groups for whom overt discrimination remains widespread is people with disabilities. Companies still post job ads specifying that people with disabilities need not apply. The overt discrimination continues both because it is perceived as socially acceptable and because so many people believe that having a disability equates to being unable to learn in school or perform at work as well as another. Children who are blind, are deaf, use a wheelchair, or have some mobility limitation are excluded from schools when a disability or difference in no way inherently limits what they can accomplish with their minds. Children with learning disabilities and differences are assumed-even more than those with physical limitations - to be unable to learn as much as others, in spite of clear evidence that they have the same distribution of intellectual abilities as other children.

Implicit bias measures how each of us thinks about another group even if we are unaware of it. Implicit bias tests examine whether an individual automatically views another group as less smart, less able, more violent, more likely to commit a crime, more likely to achieve great things. The level of implicit bias against people with disabilities is higher than against all other groups tested. In other words, tests reveal more unconscious discrimination based on disability than on 
the basis of race/ethnicity, religion, sexual orientation or gender identity, or nearly any other category.

The scope and costs of the resulting exclusion of people with disabilities are staggering. Children with disabilities in low- and middle-income countries are 30-50 percentage points less likely than children without disabilities to even enroll in school. ${ }^{31}$ These gaps persist in high-income countries. Nearly one-third of youth with disabilities in the European Union do not finish secondary school, compared to only $12 \%$ of youth without disabilities..$^{32}$ The ripple effect means that adults with disabilities, lacking equal chances at education and even the simplest and lowestcost accommodations at work, are less likely to have full-time work, and less likely to exit poverty. The loss to society is massive. Nearly one in six people have a disability. ${ }^{33}$ This is an enormous share of any country's population to underutilize.

The U.N. Convention on the Rights of Persons with Disabilities (CRPD) was one of the most rapidly adopted human rights treaties in history. Between its adoption in December 2006 and September 2014, 150 countries agreed to be legally bound by the CRPD's commitments; ${ }^{34}$ as of this writing, the list has grown to $177^{35}$ Integral to the convention is the recognition that children and adults with disabilities have the same human rights as people without disabilities, and realizing these rights is as important as realizing the rights of other groups.

In chapter 7 , we examine the extent to which constitutions have incorporated these views. How many prohibit discrimination on the basis of disability? Are all people with disabilities guaranteed the rights to education, healthcare, and work? Equal opportunity at work requires reasonable accommodation-antidiscrimination alone without reasonable accommodation leaves workplaces and opportunities entirely inaccessible. How well are constitutions addressing accommodation? Likewise, the odds of children receiving a poorer quality education and both children and adults facing stigma and societal discrimination greatly increase when students with disabilities are completely segregated from other children. How well are countries meeting their commitments to full inclusion in education?

\section{Chapter 8: Ensuring Rights and Full Participation Regardless of Social and Economic Position}

Socioeconomic status (SES) is generally understood as an individual's social and economic position relative to others. Income and wealth, educational attainment, occupation, and inherited statuses are all aspects of SES. Like disability status, SES can be lifelong, and it can change over the life course. National economic troubles can push increasing numbers into poverty. For example, the share identifying as lower SES in Egypt increased from 34\% in 2001 to 50\% in 2012. ${ }^{36}$ Meanwhile, even when countries as a whole have strong economies, a major personal illness or job loss can cause individuals and their families to move from being middle class to poor. In the United States, it is estimated that nearly $40 \%$ of $25-60$-year-olds will fall below the poverty line for at least one year of their adult lives. ${ }^{37}$ 
Discrimination on the basis of SES takes many forms. For example, in a range of countries, researchers have shown that employers discriminate against candidates with names, accents, appearance, or residency associated with lower-class status. Rights are also unequal across SES when accessing essential public goods or services is contingent on income. For example, when a public hospital refuses a patient for lack of funds, or a public school turns away a child because of inability to pay tuition, SES barriers create inequalities, with consequences for the fulfillment of fundamental rights.

These examples help illustrate why nondiscrimination alone is not enough to achieve equality-a topic explored in more detail in chapters 9 and 10. Without access to the basics, including healthcare and education, a child will not have an equal opportunity to survive and succeed. Further, rights are insufficient if people with low incomes are unable to claim them because of the costs of going to court or hiring a lawyer. Chapter 8 examines whether countries' constitutions explicitly prohibit discrimination on the basis of SES, as well as whether they guarantee that income is no barrier to education, healthcare, or political participation. The chapter further explores how constitutions and courts can ensure that SES does not determine access to justice. The chapters that follow examine in greater depth how constitutions can support access to health and education, while ensuring that people across SES can effectively fulfill their rights.

\section{Chapter 9: The Right to Education: A Foundation for Equal Opportunities}

Throughout history, governments have denied groups access to education because they knew of its fundamental role in empowering people to fight for their equal rights, and because the contributions of diverse groups within a country were not equally valued. Over time, social movements succeeded in dismantling many formal barriers to schooling through courts and legislatures, and today, more children than ever are getting an education-but important gaps remain.

Girls, students from poor families, and children with disabilities remain more likely to be out of school, especially in lower-income countries where resources are scarce. Even in countries where enrollment rates are relatively high, school quality often varies markedly, partly because of inequitable or inadequate funding. Consequently, millions of children worldwide are missing out on the widely recognized social, economic, and health benefits of education, and the persisting disparities in who gets to attend school perpetuate inequality later in life.

When education is a right for everyone, families and advocates are better equipped to ensure all children have the opportunity to fulfill their potential. What is the role for constitutions in improving educational access, quality, and attainment for all students? While fully realizing education rights takes investment, are there aspects of the right to education that all countries can and should immediately fulfill? And as economies grow, how can constitutional rights 
to education be designed to meet both the country's ability to provide more education for all and residents' need to complete higher education for better work opportunities?

\section{Chapter 10: The Right to Health: From Treatment and Care to Creating the Conditions for a Healthy Life}

Health is foundational to whether we all have an equal opportunity to succeed and participate fully in society. Our access to clean water and sanitation, adequate nutrition, preventive care and immunizations, and treatment and care for illness and injury all critically shape both our individual health and our communities' well-being.

In recent years, more and more constitutions have enshrined a right to health. In some countries, constitutional health rights have expanded access to lifesaving medicines, led to improvements in the water supply for entire neighborhoods, and spurred free immunization campaigns for low-income children. In others, the right to health has given rise to thousands of individual lawsuits that benefit only one person at a time.

In chapter 10, we explore countries' different approaches to constitutionally protecting the right to health, including whether they focus just on medical care and treatment or also promote health, prevent illness, and protect against injuryin short, address public health. Drawing on the experiences of courts and countries around the world, this chapter examines which factors shape whether the right to health improves conditions on a broad scale or benefits only a few. What types of health cases have had the greatest impact for communities and countries? How can courts effectively realize the right to health while keeping the court system from becoming overburdened by individual cases? For countries with limited resources, what constitutional and judicial approaches have ensured that the right to health is enforceable nevertheless?

\section{Chapter 11: How Far Has the World Come?}

In chapter 11, we examine the findings across all types of discrimination to understand to what extent the world's constitutions comprehensively address equal rights - and how the prevalence of these fundamental guarantees has evolved over time. While protections have strengthened in many areas, significant gaps remain. In addition to providing a comprehensive summary of findings, this chapter dives into multiple cross-cutting questions and ongoing challenges that policymakers, civil society organizations, engaged citizens, and researchers must address to effectively realize equal rights in all our countries. For example, while the oldest constitutions were generally understood to only prohibit discrimination by governments, how have newer constitutions and the courts that interpret them addressed discrimination in the private sphere? How can constitutions and courts identify and effectively respond to discrimination based on multiple or intersecting 
characteristics? And how can constitutions best support efforts to address the consequences of historic discrimination and exclusion?

\section{Chapter 12: Each of Us, All of Us: Taking Action to Strengthen Rights Globally}

Finally, chapter 12 focuses on moving from evidence to action. In this chapter, we explore what is needed beyond strong constitutional texts for advancing equality, including shifts in norms, access to justice, adequate resources and attention dedicated to implementation, and meaningful commitments to advancing change. Chapter 12 also discusses examples and strategies of successful action taken by citizens and civil society, offering practical lessons for realizing change across contexts. Around the world, activists, community leaders, and others seeking to address inequalities have led successful campaigns to strengthen constitutional protections against discrimination and for basic social and economic rights by organizing campaigns, working in coalitions, and drawing on the successful approaches of other countries. Likewise, lawyers, civil society groups, and concerned residents and citizens have used their constitutions to speak out against discriminatory rhetoric and practices, empower people to know and claim their rights, and bring court cases that have transformative nationwide impacts. This concluding chapter explores these and other ways-large and small-that people can shape and use their constitutions to make a difference.

\section{A FEW WORDS ABOUT THIS BOOK}

\section{Our Approach to Case Law}

Throughout this book, we attempt to draw lessons about the impact of constitutional rights from a wide range of countries. We do this by pairing globally comparative data on 193 countries' constitutions with court cases from 45 countries that mattered for equality. In some cases, countries offered as examples may have much in common. In other cases, they may represent largely distinct social, economic, and political contexts. And ultimately, every country is different, and shaped by a unique set of cultural and historical influences.

Countries vary importantly when it comes to certain procedural aspects of their legal systems that can significantly shape constitutional rights' accessibility and impact, as we explore throughout the chapters. For example, the difficulty of amending the constitution differs around the world. In addition, the role of case law in constitutional jurisprudence largely depends on whether the country has a "common law" system, which relies heavily on past court interpretations, or a "civil law" system, which relies primarily on the text of the law. Different countries also provide different levels of access to justice.

Wherever possible, we bring attention to these differences and their implications. At the same time, we aim to highlight above all the impacts of constitutional 
drafting choices and identify lessons and insights that are relevant to groups writing and amending constitutions.

Finally, while most cases included in this book have reached the final stage of the judicial process, we occasionally include cases decided by lower courts, which may be subject to appeal. It is possible that the outcomes of these cases may change after publication. Likewise, even those decided by the highest courts may later be overturned.

\section{Our Approach to Legal Terminology}

Although this book engages in depth with some aspects of constitutional law, our aim is accessibility to lawyers and readers from nonlegal backgrounds alike. To that end, wherever we introduce a technical legal term, such as public interest litigation or standing, we have provided a simple definition. For easy access, these terms are also included in a glossary at the back of the book.

\section{How We Hope You Will Use This Book}

We hope this book will provide you with information on whether your country, compared to others, has laid the groundwork for ensuring that governments, companies, institutions, and individuals recognize the value of every human being in every city, town, and rural community. We hope the book will offer a sense of what your and other countries are doing to ensure that every person has the education to support reaching their full potential and the health to thrive.

We also hope it will give you the tools to create opportunities for every one of us. The book is for you, your children, and your grandchildren. None of us know who our children and grandchildren will become or how life's twists and turns will affect whether each of us will have a fair chance-unless we together create the ground rules to guarantee that all of us do. 